ORIGINAL ARTICLE

\title{
Diverse Histopathological Changes Due to Cholelithiasis Seen in Surgically Removed Gall Bladder Specimens
}

\author{
Khalid Rashid ${ }^{1}$, Bilal Burki², Ghansham Ratwani ${ }^{3}$, and Saleem Ahmed Somro ${ }^{4}$
}

\begin{abstract}
Objective: To review the diverse histopathological changes found in the cholecystectomy specimens operated for gallstones

Methodology: The study was conducted at surgical ward No. 26 of JPMC for 5 years from January 2012 to December 2017. As per policy, specimens from all patients with symptomatic gall stones who underwent cholecystectomy, were sent for histopathology, the reports were reviewed and frequency of different pathological changes were noted.

Results: We observed not merely chronic cholecystitis but a plethora of different histopathological changes including tuberculosis, premalignant conditions and carcinomas, with almost no suspicion of existing pathology pre-operatively.

Conclusion: This strengthens our belief that every gall bladder specimen should be subjected to histopathological examination.
\end{abstract}

Key words: Gallbladder Specimens, Cholelithiasis, Histopathological changes

How to cite this article: Rashid K, Burki B, Ratwani G, Somro SA. Diverse histopathological changes due to cholelithiasis seen in surgically removed gall bladder specimens.

Ann Jinnah Sindh Med Uni 2020; 6(1):16-19

DOI:https://doi.org/10.46663/ajsmu.v6i1.16-19

\section{INTRODUCTION}

Cholelithiasis is the commonest disorder of gall bladder, It is prevalent both in the east and the west, although the pathogenesis may be different. Common in females above the age of forty, stones are basically of three types: pigment stones, composed of bile pigments; cholesterol stones; and mixed stones composed of cholesterol, bile pigments and bile salts in various combinations. In the Asian population, $80 \%$ cases are pigment stones while $80 \%$ of stones found in Europe and USA are cholesterol stones and mixed stones ${ }^{1}$.

Chronic cholecystitis is associated with gallstones in over $90 \%$ of cases. Supersaturation and infection of bile are the factors that lead to stone formation and also contribute to the onset of inflammatory changes in the gall bladder wall.

Professor $^{1} /$ Associate Professor ${ }^{2}$ / Assistant Professor ${ }^{3} /$ Professor and Head ${ }^{4}$ of Department of Surgery, Ward 26, Jinnah Postgraduate Medical Centre, Karachi, Pakistan Correspondence: Professor Khalid Rashid, Department of Surgery, Ward 26, Jinnah Postgraduate Medical Centre, Karachi, Pakistan

Email: drkhalidrashid@hotmail.com
A high molecular weight glycoprotein called Mucin plays an important role in protecting the gall bladder mucosa from the detergent effects of bile, while on the other hand, when secreted in large amounts, acts as a pronucleating factor and has been implicated in gallstone disease $^{2}$.

With the passage of time, stones grow in size and number within the gall bladder, causing continued inflammation, which brings about various pathological changes in its wall including malignancy.

The aim of our study is to review the diverse histopathological changes found in the gall bladder specimens operated for gallstones in the local population.

\section{METHODOLOGY}

This is an observational study of 680 cases of symptomatic gallstone disease which were operated on in the Department of Surgery, ward 26, JPMC. Both open and laparoscopic procedures were performed. The duration of study was five years, from January 2012 to December 2017.

All patients were adults above the age of 12 years and the removed specimens were sent for histopathology, 
transported in 10\% formalin solution. The specimens were dehydrated, fixed and sectioned. Standard hematoxolin eosin staining methods were applied. Histological slides were prepared and examined by postgraduate students, supervised by the consultant and reported. Histopathology reports were reviewed and results were drawn.

\section{RESULTS}

A total of 680 cholecystectomies were done in the duration of study.

\begin{tabular}{|c|l|c|}
\hline & $\begin{array}{l}\text { Histopathology of Gall Bladder } \\
\text { Associated with Cholelithiasis }\end{array}$ & $\begin{array}{c}\text { Number of } \\
\text { Patients }\end{array}$ \\
\hline 1 & Chronic cholecystitis & 660 \\
\hline 2 & Cholestrolosis & 2 \\
\hline 3 & Tuberculosis & 2 \\
\hline 4 & Xanthogranuloma & 9 \\
\hline 5 & Porcelain gall bladder & 1 \\
\hline 6 & Intestinal metaplasia & 1 \\
\hline 7 & Adenocarcinoma & 4 \\
\hline 8 & Hetrotropic pancreas & 1 \\
\hline
\end{tabular}

\section{DISCUSSION}

In this study, 660 out of 680 , the pathology in cholecystectomy specimen clearly showed chronic inflammatory changes, and in more severe cases, reactive proliferation of mucosa and eventually outpouching into the wall, forming Rokytinski-Aschoff sinuses. Although Rokytinski-Aschoff sinuses are a common finding in a chronically inflamed gall bladder, they may sometimes be mistaken for adeno carcinoma. Dorantes-Heredia $\mathrm{R}$ et al reported 8 cases of gall bladder specimen with Rokitansky-Aschoff sinuses which were misinterpreted as adeno carcinoma. They explained differentiating features of carcinoma and shared experience of having foci of adeno carcinoma within the Rokitansky-Aschoff sinuses in some specimens. They further suggested that pathologists should be well aware of these incidental lesions ${ }^{3}$.

Studying the effects of gallstones on the gall bladder mucosa, light microscopy examination of sections of the surgically removed gall bladder specimens, showed epithelial damage, and large number of mucous secreting cells. Gall bladder dyskinesia leads to gall bladder epithelium and smooth muscle layer is constantly exposed to concentrated biliary solutes, including cholesterol and potentially toxic bile salts ${ }^{1}$. Moreover abundant mucin may provide a favourable environment for nucleation of cholesterol crystals from supersaturated bile ${ }^{4}$.
Xenthogranulomatous cholecystitis develops when Aschoff sinuses rupture into the wall of the gall bladder, followed by accumulation of phospholipid filled macrophages. Such aggregation of macrophages is called xenthoma.

In our study, we found two cases of cholestrolosis associated with cholelithiasis. In most cases of cholesterolosis, the gross description shows yellow, punctuate deposits in a diffuse distribution, they look like the surface of a strawberry hence, the term strawberry gall bladder. Supersaturation of the bile with cholesterol, and abnormal lipid transport across the mucosa causes the formation of the lipid deposition ${ }^{5}$.

Epithelial hyperplasia is the most frequent change we found in $60 \%$ of our gall bladder specimens. Rahul et al found epithelial hyperplasia in 83 (69\%) gall bladder specimens ${ }^{6}$.

Discussing the significance of hyperplasia, AlboresSaavedra J, suggest that a small number of hyperplasia of the gall bladder may convert into atypical hyperplasia that progresses to in-situ carcinoma which eventually develops into invasive carcinoma ${ }^{7}$.

In rare cases of chronic cholecystitis, dystrophic calcification ensues, yielding to porcelain gall bladder, which may be a precursor to carcinoma gall bladder. It is rare and seen in 0.06 to $0.8 \%$ of cholecystectomy specimens $^{8}$. In our study, we found just one case of porcelain gall bladder out of 680 cases.

The most important risk factor for carcinoma of gall bladder is gallstones which are present in $95 \%$ of cases, evidence suggests that only $1-2 \%$ of patients of gallstones develop carcinoma. It is reasonable to conclude that the common thread tying gallstones to cancer is chronic inflammation?

Autopsy studies indicate that $1-4 \%$ of all patients with cholelithiasis develop cancer compared to less than $0.2 \%$ of those not containing stones ${ }^{10}$.

The incidence of carcinoma varies in different studies, for example, in 290 consecutive cholecystectomies for gallstones, only 2 cases of carcinoma were found ${ }^{11}$. Whereas in a study from Pakistan of 188 cases of symptomatic gall bladder disease, $13(6.9 \%)$ cases turned out to be carcinomas, 11 of which were associated with gallstones. All cases were in the sixth decade of life which is in conformity with our observation $^{12}$. Similarly, another local study of 260 cases of cholelithiasis, carcinoma was found in the range of $6 \%{ }^{13}$. 
Preoperative diagnosis of carcinoma gall bladder is difficult. Commenting on the role of ultrasonography, Samad reported 1396 cholecystectomies performed during six years, out of whom 16 patients $(1.15 \%)$ were diagnosed as gall bladder carcinoma on histopathology, whereas only three patients had preoperative ultrasonographic features to raise suspicion for malignancy. The author concludes that ultrasonography which is the most common investigation for gallstones, can miss a significant number of malignant lesions of the gall bladder and every cholecystectomy specimen should be sent for histopathology ${ }^{14}$.

In our study, we found four cases $(0.6 \%)$ of adenocarcinoma out of 680 gall bladder specimens, whereas no squamous cell ca was found. There was no preoperative suspicion of malignancy and diagnosis was made on histopathology. All patients were in the sixth decade of life.

An interesting finding in our study was the presence of heterotopic pancreatic mucosa in one cholecystectomy specimen. Heterotopic pancreas is defined as presence of pancreatic tissue in an anatomical place not related to pancreas. Most frequent locations are stomach and small bowel. Gall bladder is rare. About 30 cases have been reported so $\mathrm{far}^{15}$. The preoperative diagnosis of heterotopic pancreas is difficult and the significance of incidental finding is unclear and requires a systemic review of the subject ${ }^{16}$.

Intestinal metaplasia was found in one specimen in our study, it is considered a premalignant condition therefore needs some scrutiny. Jorge Albrose showed intestinal metaplasia in 49 specimens removed for cholelithiasis. A whole range of changes were observed from the presence of mature goblet cells to those containing argentafin cells, peneth cells and gland like structures. He supports the hypothesis that cholelithiasis induces the formation of stem endodermal cells which may differentiate into mature intestinal or gastric mucosa ${ }^{17}$.

Khan et al reported 114 cholecystectomy patients out of 293 (39\%) with intestinal metaplasia, this itself shows high frequency of metaplasia in Pakistan. Significant association with age more than 60 years, borderline association with moderate to high red chili pepper consumption and North Indian origins were noted $^{18}$.

Tuberculosis of gall bladder with gallstones is very rarely mentioned in world literature. Around 150 cases have been described since 1870 . Out of 680 cases operated for gallstone disease in five years, only two cases of tuberculosis were found in our study. We could not diagnose them preoperatively, as they appeared as usual cholelithiasis on ultrasonic examination.

After the diagnosis on histopathology, patients were treated with anti-tuberculous chemotherapy and recovered uneventfully.

Usman Ismat Butt et al reported a case in a Pakistani man who had cholecystectomy for gall bladder mass with stones. They were suspecting carcinoma but on histopathology, it turned out to be tuberculosis. Patient was treated with anti-tuberculous drugs and made an uneventful recovery. The authors suggested that tuberculosis is very common in Pakistan. It is therefore, likely that the incidence of tuberculosis of gall bladder is more than that reported in the Western literature ${ }^{19}$.

\section{CONCLUSION}

This is a descriptive study of 680 cases, operated for cholelithiasis, during a period of 5 years in our department, where histopathology specimens were later reviewed to observe not merely chronic cholecystitis but a plethora of histopathological changes including tuberculosis, premalignant conditions and carcinomas. This strengthens our belief that every gall bladder specimen should be subjected to histopathological examination.

\section{References}

1. William NS, O'Connell PR, McCoskie AW. Baily and love short practice of Surgery, $27^{\text {th }}$ Edition. CRC Press. $2018 ; 1198$.

2. Zaki M, Al-Refeidi A. Histological Changes in the Human gall bladder Epithelium associated with Gallstones. Oman Med J.2009;24(4): 269-73.

3. Dorantes-Heredia R, Chablé-Montero F, Henson DE, Albores-Saavedra J. Rokitansky-Aschoff sinuses mimicking adenocarcinoma of the gall bladder: A study of 8 cases, J. Am J Surg Pathol. 2013;37(8):1269-74.

4. LaMont JT, Smith BF, Moore JR: Role of gall bladder mucin in pathophysiology of gallstones; Hepatology. 1984;4(5 Suppl):51S-56S.

5. Ibrahim H. Zahrani, Ibrahim Mansoor: gall bladder pathologies and cholelithiasis. Saudi Med J. 2001;22 (10):88-89.

6. Khanna R, Chansuria R, Kumar M, Shukla H.S: Histological changes in gall bladder due to stone disease. Ind Journal Surg. 2006;68(4): 201-204.

7. Albores - Saavedra J, Molberg K, Henson DE. Unusual malignant epithelial tumors of the gall bladder. Semin Diagn Pathol.1996;13(4):326-38. 
Histopathological changes in surgically removed gall bladder specimens

8. Palermo M, Núñez M, Duza GE, Dixon MG, Bruno MO, Trasitano FJ. Porcelain gall bladder: a clinical case and a review of the literature; Cir Esp. 2011;89(4):213-7.

9. Viny K, Abbas A, Fausto N ,Aster J. Robbin \& Cotran Pathologic Basis of Disease, $8^{\text {th }}$ Edition. Saunders. 2010;1464.

10. Silk YN, Douglas HO, Nava HR, Driscole DL, Tartarian G. Carcinoma of the gall bladder. Ann Surg. 1989;210(6):751-757.

11. Haq N, Khan BA, Imran M, Akram A, Jamal AB, Bangash F. Frequency of gall bladder carcinoma in patients with acute and chronic cholecystitis. J Ayub Med Coll Abbottabad. 2014;26(2):191-3.

12. Faisal GS, Nargis SS. An Audit of cholecystectomy specimens.Pak J Surg.2002;7(2):18-20.

13. Khalid SM. Pattern of gall bladder Diseases at NawabShah, analysis of 260 patients. Pak J Surg. 2006; 22(4):212-14.

14. Samad A. Gall bladder carcinoma in patients undergoing Cholecystectomy for Cholelithiasis; J Pak Med Assoc, 2005;55(11):497-99.
15. Sanchiz Cardines EM, Humanes RS, Fernandez AL, Nieto RD, Suarez Munoz MA.Ectopic pancreas in gall bladder, clinical significance, Diagnostic and therapeutic Implications. Rev Esp Enferm Dig.2015;107(11): 701703.

16. Shiwani MH, Gosling J. Hetrotropic pancreas of the Gall Bladder associated with chronic cholecystitis; J Pancreas.2008;9(1):30-32.

17. Albrose-saavedra J, Nadji M, Henson DE,Ziegelsweissman J, Mones JM. Intestinal metaplasia of the gall bladder a morphologic and immunocytochemical study. Hum Pathol.1986;17(6):614-620. doi: 10.1016/ s0046-8177(86)80134-4

18. Khan MR, Raza SA, Ahmed Z, Naeem S, Pervez S, Siddiqui AA, et.al. gall bladder intestinal metaplasia in Pakistani patients with gallstones; Int J Surg.2011; 9(6): 482-485.

19. Butt UI, Hameed B, Farooka MW, Ayyaz M, Chughtai A and Akbar MB. Tuberculosis of gall bladder Mimicking Carcinoma. J Coll Physicians Surg Pak.2017;27(9):84-85 